\title{
Experimental modeling of refrigerants at high ambient temperature
}

\author{
Sahar Ajrawi*, Sorour Alotaibi** and Walid Chackroun** \\ *Kuwait National Petroleum Company (KNPC), Ahmadi, Kuwait \\ **Mechanical Engineering Department, Faculty of Engineering and Petroleum, Kuwait University, Kuwait \\ Kuwait National Petroleum Company. \\ Corresponding Author: sr.alotaibi@ku.edu.kw
}

Submitted: 05/10/2019

Revised: $29 / 10 / 2020$

Accepted: 15/11/2020

\begin{abstract}
High ambient temperature is well known to have an adverse impact on air conditioners; it lowers their cooling capacity along with their coefficient of performance. Moreover, air conditioning plays a significant role in damaging the environment as it contributes to both global warming and ozone depletion. In the past few decades, the Montreal agreement was introduced to protect the ozone layer from substances that contribute to its depletion. Developing countries are now facing the challenges of phasing out HCFCs such as R22 in the air conditioning sector. The aim of this study is to find an alternative refrigerant that can replace R22 after its phase out. The new refrigerant must have low environmental impacts and should be able to withstand operation in high ambient temperature countries. In this study, the hydrocarbon refrigerant R290 and the hydrofluorocarbon R410A were selected as alternatives. Furthermore, experimental testing was carried out on the baseline refrigerant R22 and R410A using a $7 \mathrm{~kW}$ ducted split unit at three outdoor conditions: $35^{\circ} \mathrm{C}, 48^{\circ} \mathrm{C}$, and $52^{\circ} \mathrm{C}$. From the experimental results, a model based on R22 and R410A was developed using Engineering Equation Solver (EES). The model was successful in verifying the experimental results within a 15\% error range and was tested again with external data from (Eltalouny \& Nielsen, 2016) [10]. After confirming its validity, the model was simulated to predict the performance of the alternative refrigerant R290 under the same experimental conditions and input data. To test the model's validity on R290, results from Eltalouny $\&$ Nielsen (2016) were used. The model succeeded in predicting the COP and power consumption. The refrigerants demonstrated deterioration in their performance at elevated temperatures compared to their performance at a typical operating regime. With proper safety measures, and enhancement to the compressor efficiency, R290 can be considered as a promising alternative.
\end{abstract}

Keywords: High ambient temperature; vapor compression cycle; refrigerants.

\subsection{INTRODUCTION}

With the development of climate control technologies, air conditioning was found to have adverse effects on the environment as it contributes to both global warming and ozone depletion (Chakravarthy \& Kumar, 2012). Environmental impacts can be classified into direct and indirect. Direct impacts are those that occur due to a leakage of refrigerant into the atmosphere causing ozone depletion and global warming by the greenhouse effect. On the other hand, indirect impact occurs as a result of energy consumption of air conditioning and refrigeration systems. Carbon dioxide is released in the atmosphere, hence causing global warming (Grof, 2009).

In the past few decades, the air conditioning and refrigeration industry progressed in minimizing the environmental impact. In 2015, a freeze of HCFCs was initiated, leading to a complete phase out by 2030 in the developing 
countries. As for the developed countries, a total ban is planned for 2020. A total phase out of HCFCs that are used in air conditioning and refrigeration equipment is scheduled in 2040. Developed countries began using HFCs, as a replacement for HCFCs. Proposals for the cutback of HFCs were also considered under the agenda of the Montreal Protocol. Despite the fact that some HFCs have zero ozone depletion potential, their global warming potential may be relatively large (Grof, 2009).

Since R22 is becoming more widely phased out under the Montreal Protocol, R410A has been the refrigerant of choice worldwide. In Kuwait, it is currently being used as an alternative to R22.

In 2016, the Kigali agreement was endorsed by Montreal Protocol nations. The agreement counters climate changes by phasing down HFCs mostly used in the air conditioning and refrigeration industry. HFCs are greenhouse gases that are extremely more powerful in trapping heat in the atmosphere than carbon dioxide. This is a significant step, as the warming of the planet will be mitigated at present and for generations ahead (Historical agreement on HFCs reached in Kigali (2016, October 15)) (Network, A. J. M. Kigali deal: Agreement reached to phase out HFCs).

Hydrocarbon (HC) based refrigerants, such as R290, with low global warming potential, zero ozone depletion potential, excellent thermodynamic properties, and relatively high performance with respect to R22, are favorable long-term alternatives. The performance of an air conditioning or refrigeration system decreases with increasing outdoor temperatures. Refrigerants with a low critical (design) temperature experience a larger degradation of cooling capacity. R290 has a high critical temperature, similar to that of R22. A high critical temperature yields higher COP due to smaller compressor superheat and smaller flash gas losses. In order to have greater heat transfer at a constant temperature, and lower power consumption, the critical temperature of a refrigerant should be above the condensing temperature.

LeRoy et al. (Motta \& Domanski, 2000) examined unitary systems with R22 as the working fluid. The testing was performed at high operating temperatures to inspect power and capacity loads. The aim of the research was to validate the performance estimates of three public area heat pump simulation models. Data of ten systems from the analyses at $35^{\circ} \mathrm{C}$ were used, three of which were examined at $46.1^{\circ} \mathrm{C}$ and three others were tested at $51.7^{\circ} \mathrm{C}$, under the same indoor conditions, which are $19.4^{\circ} \mathrm{C}$ wet-bulb and $26.7^{\circ} \mathrm{C}$ dry-bulb. The capacity and energy efficiency ratio were noted. As a result, the performance drop of systems differs considerably from one system to another at high ambient temperature.

Faramarzi et al. (2004) proposed a performance evaluation of typical five-ton roof top air conditioning units under high ambient temperatures. The aim of the study was to identify the effect of high ambient temperatures on the electric demand, efficiency, and cooling capacity degradation of five-ton roof top air conditioning units. Several HVAC manufacturers' products were tested. The unit contained a scroll compressor and had a larger evaporator coil surface, making it a high efficiency unit. In conclusion, both the high efficiency and standard efficiency units degraded with an increase in ambient temperature. However, the standard unit cooling capacity dropped faster than the high efficiency unit.

Wells et al. (1999) examined the performance of split systems, as well as window type air conditioners. The testing was carried out to compare between R22 and R410A. Laboratory analysis of window and split units plus theoretical simulations was done. At an outdoor temperature of $51.7^{\circ} \mathrm{C}\left(125.0^{\circ} \mathrm{F}\right)$, a $14 \%$ decrease in the cooling capacity of R22 was noted. However, the cooling capacity and EER of R410A experienced a drop of $22 \%$. Installing a TXV against a short tube decreased the performance loss.

Meurer et al. (1999) compared the performance of R22 and R410A operating at high condensing temperatures, reaching up to $60^{\circ} \mathrm{C}$. The system was composed of an evaporator that is heated using methanol, a reciprocating compressor, a water-cooled condenser, a thermostatic expansion valve, and a liquid line accumulator. It was noted that, at a condensing temperature of $27^{\circ} \mathrm{C}$ and an evaporation temperature of $9^{\circ} \mathrm{C}$, the coefficient of performance of R410A was higher than that of R22 by $16 \%$. However, as the condensing temperature increased to $57^{\circ} \mathrm{C}$, the coefficient of performance of R22 was higher than R410A by $1 \%$. In conclusion, an undesirable effect occurs to the performance of R410A when equal rotational speed is used in the compressor. Hence, R410A performs well at lower compressor speed. 
Chin and Spatz (1999) investigated some of the pros and cons of R410A as an operating refrigerant in air conditioning systems. The authors compared R22 and R410A by using compressor performance data and a heat pump model. The favorable thermophysical properties of R410A were exploited by optimizing the heat exchanger. The condenser and evaporator were optimized, and simulations for R410A and R22 systems were performed. In comparison to R22, the optimized evaporator and condenser, as well as the high performance of the compressor, compensated for the efficiency of R410A, at condensing temperatures ranging from low to moderate. However, at condensing temperatures above $47^{\circ} \mathrm{C}$, a drop in the coefficient of performance was noted by the optimized R410A system relative to $\mathrm{R} 22$.

Payne and Domanski (2002) compared the performance of R22 and R410A at elevated ambient temperatures. The deterioration of performance in R410A was greater than that of R22. The study shows that those refrigerants with lower critical temperatures experience greater deterioration in performance than refrigerants with higher critical temperatures. Payne and Domanski concluded that the coefficient of performance of R410A is smaller than that of R22 due to its lower critical temperature.

A simulation study to examine the coefficient of performance and cooling capacity of an air conditioner operating at R22 and four other refrigerants was performed by Motta and Domanski (2000). The refrigerants tested include $\mathrm{R} 410 \mathrm{~A}, \mathrm{R} 407 \mathrm{C}, \mathrm{R} 290$, and R134a. The analysis was carried out at a range of temperatures from $25.0^{\circ} \mathrm{C}\left(77.0^{\circ} \mathrm{F}\right)$ to $55.0^{\circ} \mathrm{C}\left(131.0^{\circ} \mathrm{F}\right)$. When R410A was compared to R22, it was signified that the performance and EER dropped $2 \%$ at $25^{\circ} \mathrm{C}$ and $6.5 \%$ at $55^{\circ} \mathrm{C}$. The simulation also included a liquid line added to the heat exchanger's internal suction line. The installation of an internal heat exchanger can reduce the losses in the coefficient of performance and energy efficiency ratio by approximately $50 \%$.

Hadya, Usha Sri, and Akella (2012) examined the performance of eco-friendly refrigerants such as R290 and R32, which were compared to R22. The theoretical analysis was performed on $1 \mathrm{TR}$ air conditioning units. The evaporating temperature considered is $-15^{\circ} \mathrm{C}$, and the condensing temperatures studied are $30^{\circ} \mathrm{C}$ and $40^{\circ} \mathrm{C}$. As the temperature increased, R290 showed the best COP. The pressure ratio was also calculated. R32 had the highest pressure ratio when compared to R22 and R290. This indicates that the air conditioning system operated using R32 requires higher power.

Al-Joudi and Al-Amir (2014) created a model to approximate the effect of high ambient temperatures on 2 TR air conditioning units operated by R22, R290, R407C, and R410A. The theoretical model results were verified with experimental data performed at the same cooling capacity. However, the ambient temperature started at $35^{\circ} \mathrm{C}$ and ranged up to $55^{\circ} \mathrm{C}$, with an increase of $5^{\circ} \mathrm{C}$ for each test. As a result, $\mathrm{R} 407 \mathrm{C}$ showed a performance similar to that of R22. On the other hand, R410A consumed the most power with the least COP due to its low critical temperature in comparison to the alternative refrigerants tested. R290 showed the best performance at higher ambient temperatures, proving to be the most suitable alternative for $\mathrm{R} 22$.

Schultz (2014) investigated the performance of R22 and R410A along with low global warming potential alternative refrigerants at high ambient temperatures. The study was performed on $15.5 \mathrm{~kW}$ air-cooled water chiller/ heat pump at an ambient temperature that ranged from $24^{\circ} \mathrm{C}$ to $46^{\circ} \mathrm{C}$. The refrigerants considered in this study include the baseline refrigerant R410A, R32, and 6 types of refrigerant blends identified as ARM- 70a, ARM-32a, DR-4, DR-5, HPR1D, L-41a, and L-41b. More tests were carried out, where the compressor was changed to one designed for pressures in the same ranges of R22. The refrigerants considered include the baseline refrigerant R22, as well as blends identified as ARM-32a, DR-4, DR-7, LTR6A, L-20, and LTR4X. The alternative refrigerant blends comprise R1234ze(E), R1234yf, R134A, R32, R125, R152A, and R744. As a result, R410A showed the worst performance at high ambient temperatures. On the other hand, L-20's characteristics were comparable to R22. In conclusion, R32 demonstrated high discharge temperatures, which need to be alleviated by modifying the cycle and by improving the design to function at high ambient temperatures, as well as high pressures.

Sun and Cui (2019) studied the energy and exergy performance of R513a used as a drop-in replacement for R134a in an economized vapor compression refrigeration system. The role of each component in the cycle to increase the 
exergy destruction rate has also been identified. R513a (R134a/R1234yf) has similar thermophysical characteristics to R134a, with a lower GWP. It was found that a system in which R513a replaces R134a will suffer reduction in both capacity and efficiency (energy and exergy efficiency) under a majority of operating conditions and, however, will exhibit less irreversibilities at high ambient and space temperatures, and better exergy efficiency at low ambient temperatures. To enhance the energy and exergy efficiency of an R513a system, the analysis results show that the compressor is the main component to be redesigned or reselected, followed by the economizer, valves, and evaporator. The condenser influence is negligible.

A. E. Kabeel et al. (2016) analyzed the performance of R134a and compared it to another low GWP refrigerant R1234ze in a trail to provide a solution to high GWP of refrigerants presently used in cold rooms. It was noted that R1234ze has higher COP than R-134a by 7-33 \%. Moreover, an exergy analysis showed higher second law efficiency for R1234ze. Mohanraj et al. (2009) reviewed various experimental and theoretical studies conducted around the world with environmentally-friendly alternatives such as hydrocarbons (HC), hydrofluorocarbons (HFC), and their mixtures, which are going to be promising long-term alternatives. Moreover, the technical difficulties of mixed refrigerants and future challenges of the alternatives are discussed. The problems concerning the usage of environmental friendly refrigerants are also assessed. Based on the results regarding the performance, it can be understood that HC mixtures and R152a are found to be better substitutes for R12 and R134a in domestic refrigeration sector. R290, R1270, R290/ R152a, R744, and HC/HFC mixtures are found to be the best long-term alternatives for R22 in air conditioning and heat pump applications.

S.Karagoz et al. (2004) investigated the possibilities of using R134a as a working fluid to replace R22 in vapor compression heat pumps. The working fluids considered in the study were pure R22, pure R134a, and some binary mixtures of R22/R134a. The performance of the system was determined by mixture ratio, COP, and evaporator air inlet temperature. The pure refrigerants and refrigerant mixtures were compared based on their COP. Experimental results revealed that the mixture ratio affected the COP considerably, and the COP could be improved by using pure $\mathrm{R} 134 \mathrm{a}$ or a proper mixture of R134a/R22 instead of pure R22. The maximum COP occurred at a mixture ratio of $50 / 50 \% \mathrm{R} 134 \mathrm{a} / \mathrm{R} 22$. The COP improved by an average of $25 \%$ for a mass percentage of $50 \%$ of R134a.

Wanga et al. (2019) examined the performance of an $11 \mathrm{~kW}$ R410A heat pump system with a two-stage vaporinjected scroll compressor experimentally. The vapor-injected scroll compressor was tested with both cycle options: flash tank and internal heat exchanger configurations. The cooling capacity and COP improved $14 \%$ and $4 \%$ COP at $46.1^{\circ} \mathrm{C}$. Furthermore, the heating capacity and COP improved by $30 \%$ and $20 \%$ at $17.8^{\circ} \mathrm{C}$, in the vapor-injected $\mathrm{R} 410 \mathrm{~A}$ heat pump system as compared to the conventional system, which has the same compressor displacement volume.

The current paper presents experimental modeling of the vapor compression refrigeration cycle using Engineering Equation Solver (EES). The main objective of this work is to find an alternative refrigerant after the phase out of R22 that operates efficiently at high ambient temperatures. The alternative refrigerants analyzed are R410A and R290.

Experimental testing was carried out on the baseline refrigerant, R22, as well as R410A. Data was taken from the experimental results to model a program using EES. The model enables the user to predict the performance of R22, R410A and was further developed to predict the performance of R290. The model results of R22 were verified with the experimental results. The performance of R290 was compared to R22. In addition, the model was validated for R22 and R290 using results from a reference paper.

\subsection{AIR CONDITIONING RESEARCH AND TESTING CENTER}

The experiments in this report were performed at Kuwait University in an air conditioning testing and research center. The psychrometric testing facility is designed for use in the research, development, and testing of unitary air conditioners and heat pumps. The psychrometric test facility consists of two rooms, in an end-to-end configuration, where dry-bulb temperature and humidity are independently controlled. One of the two rooms simulates indoor temperature and humidity conditions, while the second room simulates outdoor temperature and humidity conditions. Airflow measurements are provided by Code Testers (Air Enthalpy Tunnels) as specified in ASHRAE Standard 
37 (Methods of Testing for Rating Electrically Driven Unitary Air Conditioning and Heat Pump Equipment). [Air Conditioning and Refrigeration Institute (ARI). 1989, Ashrae. 1988.],[ Ansi/Ashrae Standard 37-1988)].

A code tester is located in both the indoor and the outdoor unit under test (UUT) airflow measurement. There are two air conditioning plenums in both the indoor and the outdoor rooms. The plenums include full heating, cooling, dehumidification, and humidification capabilities so that heat pump and air conditioner testing can be accomplished without having to reverse the UUT direction in the common partition wall between the test rooms. It is controlled by a software facility called Climatic Testing Systems (CTS). The CTS offers data acquisition that is fully automated. It also provides data collection and calculations in a simultaneous manner. The psychrometric test rooms are also equipped with a central refrigeration system that is used to provide cooling and heating capabilities to both rooms. The test facility can handle air conditioning units with a capacity up to 10 tons and an indoor maximum flow rate of 3900 CFM. Figure 1 shows a schematic of the psychrometric test facility used in Kuwait University lab (Ajrawi, Alotaibi \& Chakroun, 2016).

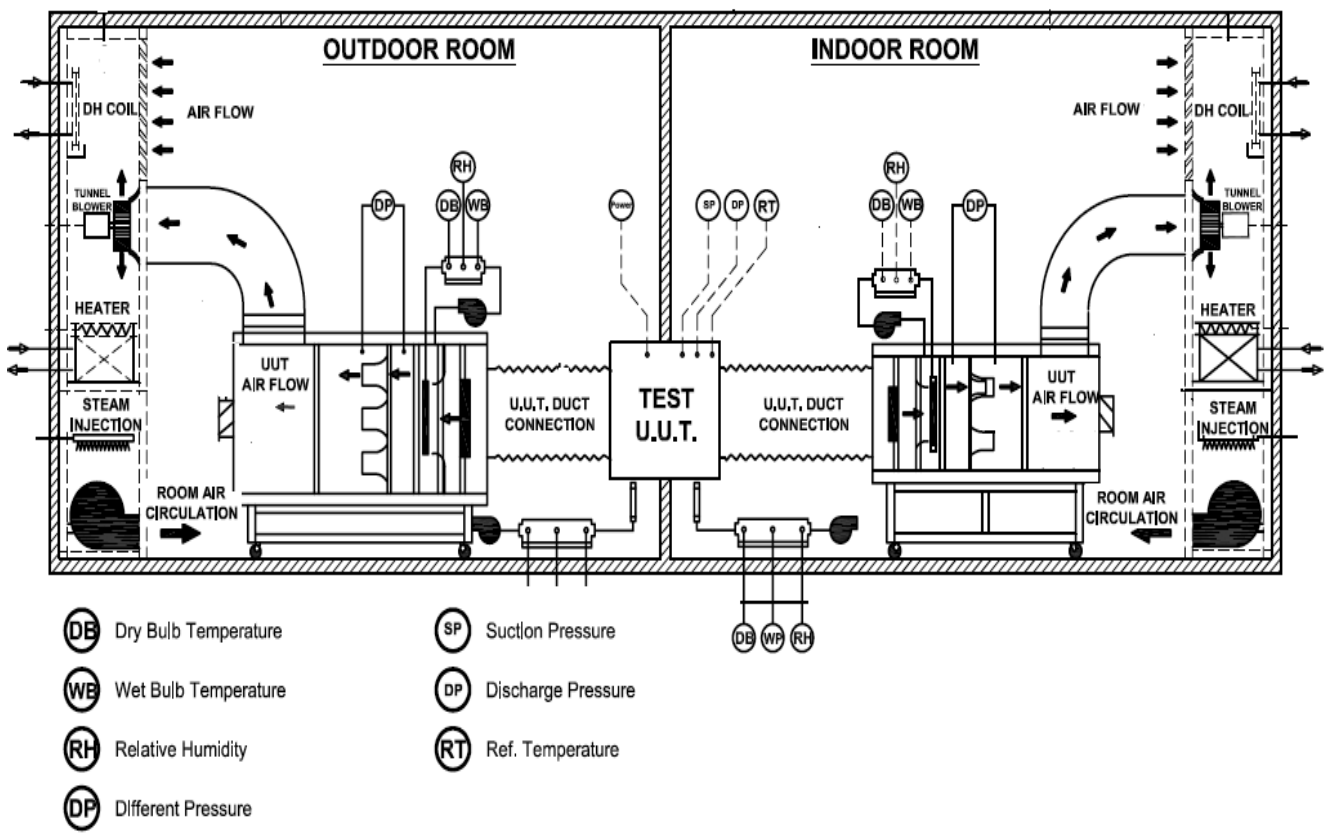

Fig. 1. Schematic showing details of the indoor and outdoor chambers of the psychrometric test facility.

\subsection{Testing Details}

The tests were conducted on a ducted split air conditioning system, donated from a local manufacturing company. The experimental testing was carried out on the baseline refrigerant R22, as well as one of the rising HFCs that does not contribute to ozone depletion, R410A. Pressure taps were installed at the suction, discharge, liquid, and after capillary tubes lines.

The performance of R290 was simulated using a model based on the R22 experimental results obtained, which will be portrayed in section 3.0.

\subsection{PLOTS OF EXPERIMENTAL RESULTS}

The cooling capacity of the unit was measured experimentally, and the result was noted from the CTS.

Figure (2) represents ideal and actual refrigeration cycles to explain the processes taking place, along with the adjustments made. 


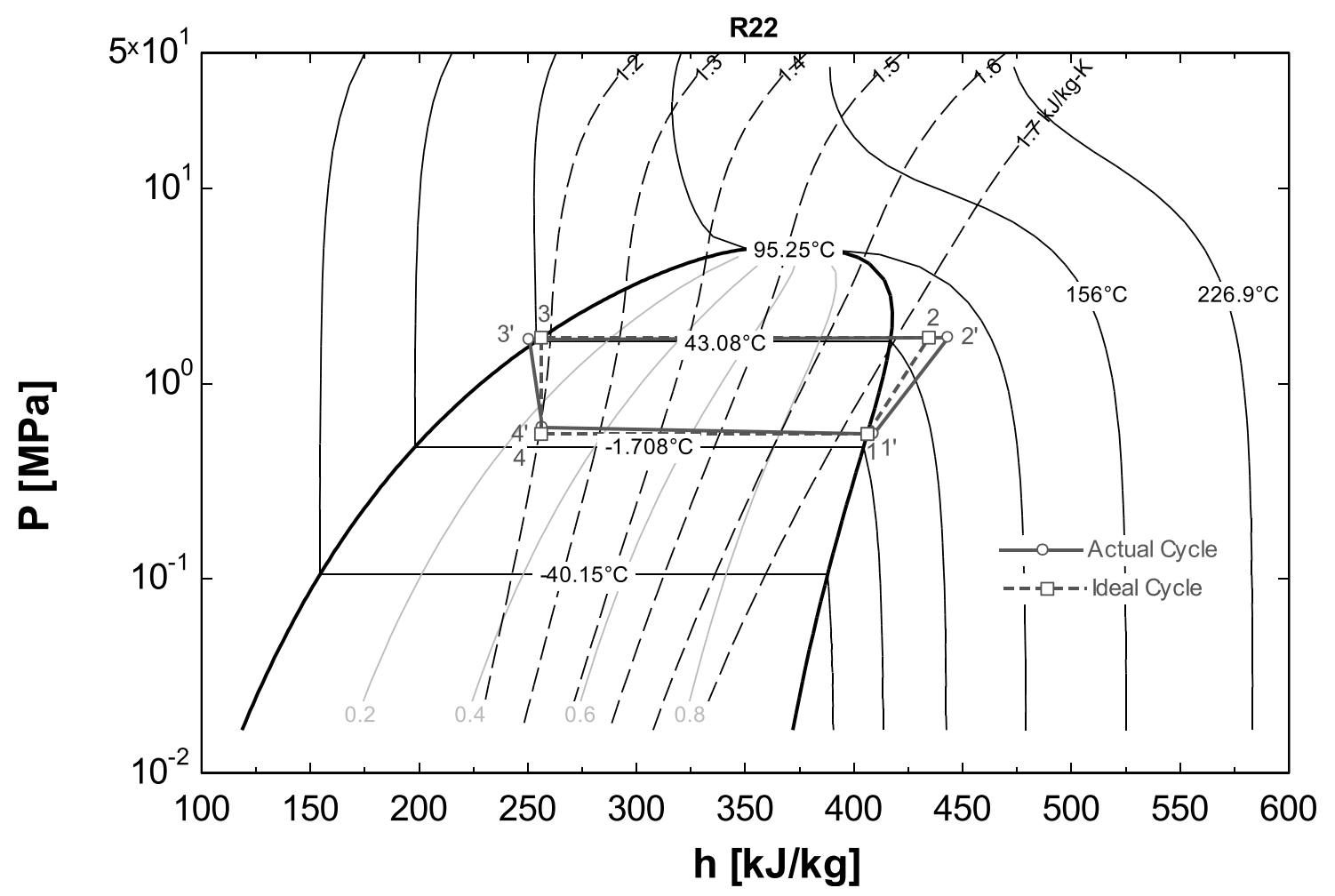

Fig. 2. Ideal Vs. Actual Cycles.

State 1 in the cycle portrays the evaporator outlet. In the ideal cycle, the refrigerant in this state is a saturated vapor; therefore, the quality equals 1 . State 2 represents the compressor outlet, where the refrigerant is isentropically compressed. The refrigerant at this condition is a superheated vapor. In State 3, the refrigerant is at the condenser outlet and is characterized as a saturated liquid. Therefore, the quality at this state equals 0 . In the ideal cycle, the pressure drop is disregarded. The pressure was assumed to be isobaric at states 2 and 3. State 4 represents the outlet of the throttling valve (capillary tube), where the refrigerant is a saturated mixture. The pressure at state 4 is assumed to be isobaric to state $1(\mathrm{P} 4=\mathrm{P} 1)$, and isenthalpic to state $3(\mathrm{~h} 4=\mathrm{h} 3)$. From the results obtained at each state, the coefficient of performance, mass flow rate, and work were calculated.

The ideal cycle was modified by including temperature changes (superheating and subcooling), pressure differences, and enthalpy changes to develop the actual cycle. From state 1' to state 2', heat was added to ensure that no liquid was present in the compressor $\left(4{ }^{\circ} \mathrm{C}\right.$ superheat). The degrees of superheat were added to the ideal temperature (T1). The enthalpy of state 2' was computed from the isentropic efficiency equation, which is

$\eta_{C} \cong \frac{h_{2 s}-h_{1}}{h_{2^{\prime}}-h_{1}}$

Rearranging the equation,

$$
h_{2 \prime}=\left(\frac{h_{2 s}-h_{1}}{\eta_{c}}\right)+h_{1}
$$

The temperature of state 2' was then found. The pressure was measured across the condenser, and the percentage pressure change was calculated.

For (T3'), the liquid was cooled by 4 degrees to ensure the safety of the throttling valve. The subcooling value was subtracted from the ideal temperature at the condenser outlet (T3) to obtain the actual temperature. The pressure 
across the evaporator was measured, and the percentage pressure change was calculated, which was further entered in the model as a correction factor.

Similarly, the percentage change in enthalpy across the capillary tube was calculated from the experiment and entered in the model to determine the enthalpy at the evaporator inlet. With the information obtained, the coefficient of performance, mass flow rate, compressor power, and total power were computed for the actual cycle.

Figure 3 illustrates the cooling capacities of the R22 and R410A units against the three ambient temperatures. As can be seen from the plots, an increase in the ambient temperature decreases the cooling capacity for both refrigerants. For R22, the cooling capacity at $35^{\circ} \mathrm{C}$ was equal to $7.16 \mathrm{~kW}$. It dropped to $6.24 \mathrm{~kW}$ at $48^{\circ} \mathrm{C}$, and to $6.09 \mathrm{~kW}$ at $52^{\circ} \mathrm{C}$. The percentage drop in the cooling capacity between $35^{\circ} \mathrm{C}$ and $48^{\circ} \mathrm{C}$ is $12.85 \%$, and from $48^{\circ} \mathrm{C}$ to $52^{\circ} \mathrm{C}$, the drop is $2.4 \%$. However, for R410A, the cooling capacity at $35^{\circ} \mathrm{C}$ was lower than that of $\mathrm{R} 22$ with a value of $5.7 \mathrm{~kW}$. The cooling capacity experienced further deterioration at $48^{\circ} \mathrm{C}$ and $52^{\circ} \mathrm{C}$, dropping from $5.07 \mathrm{~kW}$ to $4.88 \mathrm{~kW}$. The percentage drop in the cooling capacity from $35^{\circ} \mathrm{C}$ to $48^{\circ} \mathrm{C}$ and $48^{\circ} \mathrm{C}$ to $52^{\circ} \mathrm{C}$ is $11.1 \%$ and $3.8 \%$.

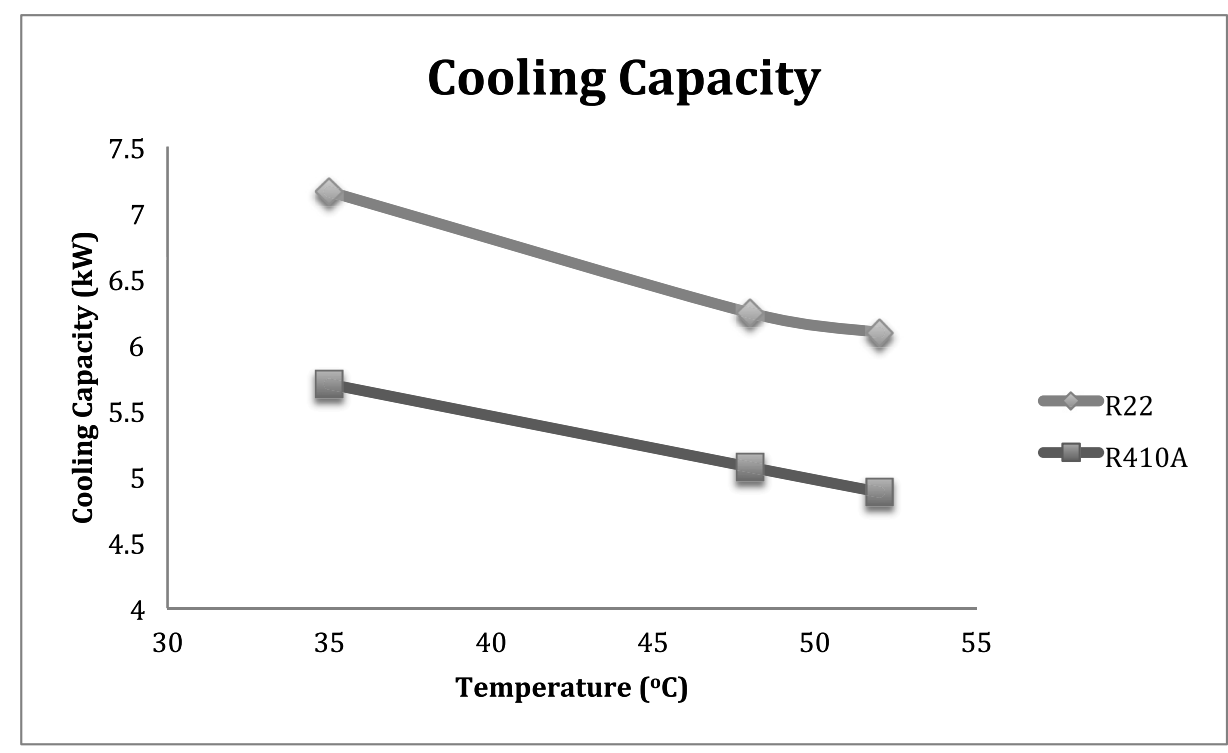

Fig. 3. Cooling capacity of the R22 and R410A against the ambient temperature.

\subsection{MODEL DEVELOPMENT}

The software used to model the vapor compression refrigeration cycle in this study is Engineering Equation Solver (EES).

The program was constructed for an ideal vapor compression refrigeration cycle at the four main states. From the experimental results, the actual cycle was developed and linked to the program, by including the pressure drop in the evaporator and condenser, degrees of superheating and subcooling, and the slight change in enthalpy at states 3 to 4. Those changes in states were obtained from experimental testing of typical 2-ton air conditioning systems, where the average was taken and hence applied in the model. The program requires the user to provide the suction pressure $(\mathrm{MPa})$, discharge pressure $(\mathrm{MPa})$, cooling capacity, and type of refrigerant. The suction and discharge pressures were necessary to set the pressure boundaries of the cycle. Moreover, the cooling capacity was required to further obtain the mass flow rate and power. The type of refrigerant was expressed to provide thermophysical properties of the operating fluid.

Some parameters such as the isentropic efficiency, evaporator fan power, and condenser fan power were fixed in the program. During the experimental testing, the evaporator and condenser fan power values were noticed to be 
approximately constant at the three ambient temperatures; therefore, they were set as $0.27 \mathrm{~kW}$ and $0.35 \mathrm{~kW}$. For the isentropic efficiency, the value was tuned to satisfy the experimental results and was set to be $74 \%$ for R22 and R410A. A program was modeled at each ambient temperature $\left(35^{\circ} \mathrm{C}, 48^{\circ} \mathrm{C}\right.$, and $\left.52^{\circ} \mathrm{C}\right)$.

The experiments for R290 were not conducted due to the refrigerant's flammability. In addition, unexpected consequences may occur during the conversion procedure. Therefore, a simulation was performed using the same programs of R22.

The model was tested for R290 at the three conditions, using the same experimental data of R22. The results of R22 and R290 at the three ambient temperatures were noted and compared.

\subsection{RESULTS}

Figure 4 shows the results of the COP versus the ambient temperature for R22, R410A, and R290. The COP in this case was calculated using the total power $\left(\mathrm{W}_{\text {Compressor }}, \mathrm{W}_{\text {condenser,fan, }}, \mathrm{W}_{\text {evaporator,fan }}\right)$. The experimental and model changes of COP are shown for R22 and R410A. However, for R290, the model results are portrayed only, since no experiments were conducted. The COP of all refrigerants decreases with an increase in the ambient temperature. The trend of the experimental and model results was similar with negligible variations. The model gave slightly higher COP results than the experimental values. R290 had the highest COP values at $35^{\circ} \mathrm{C}$ and $52^{\circ} \mathrm{C}$ and an equivalent value with R22's model result at $48^{\circ} \mathrm{C}$. R410A had the least COP values at the three ambient temperatures. At $35^{\circ} \mathrm{C}$, the percentage error between the experimental and the model COP for R22 is $4.04 \%$. Moreover, at $48^{\circ} \mathrm{C}$ and $52^{\circ} \mathrm{C}$, the percentage error is $8.7 \%$ and $9.54 \%$. For R $410 \mathrm{~A}$, the percentage errors between the experimental and model results at $35^{\circ} \mathrm{C}, 48^{\circ} \mathrm{C}$, and $52{ }^{\circ} \mathrm{C}$ are $11.51 \%, 13.43 \%$, and $12.97 \%$.

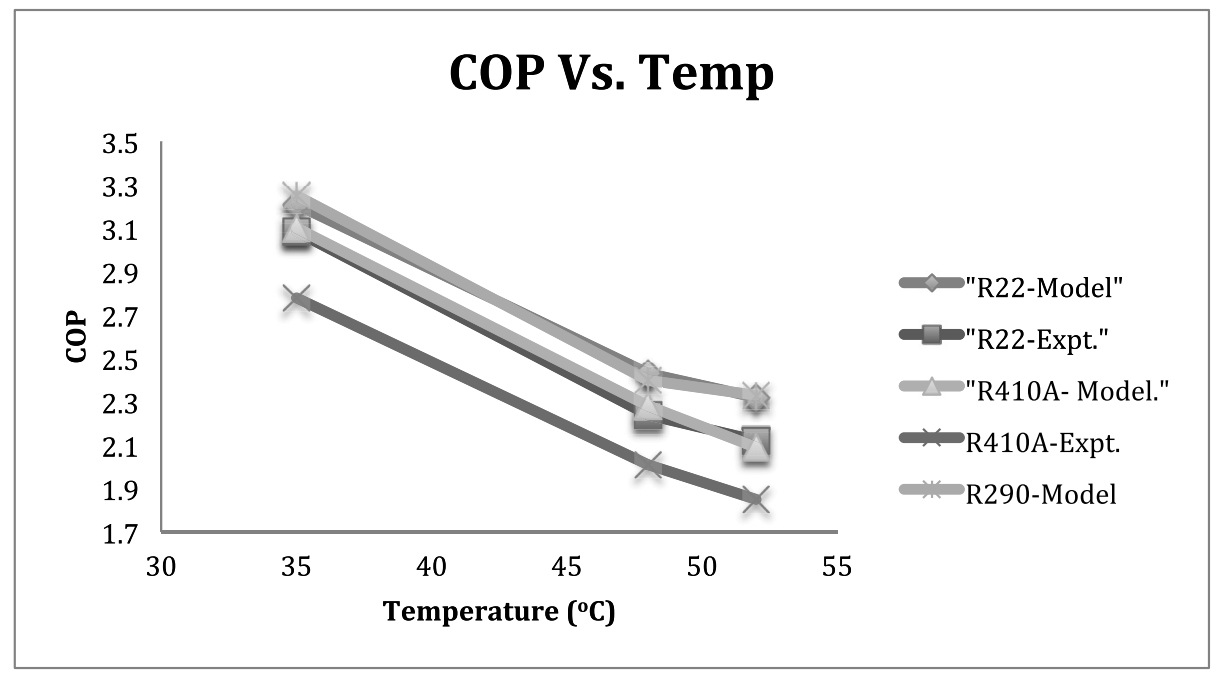

Fig. 4. COP calculated using total power versus ambient temperature for all refrigerants.

Similar to Figure 4, Figure 5 portrays the COP calculated using the compressor power versus the ambient temperature. The percentage errors between the experimental and model results at $35^{\circ} \mathrm{C}, 48{ }^{\circ} \mathrm{C}$, and $52{ }^{\circ} \mathrm{C}$ are $12.04 \%$, $8.59 \%$, and $11.23 \%$, respectively. 


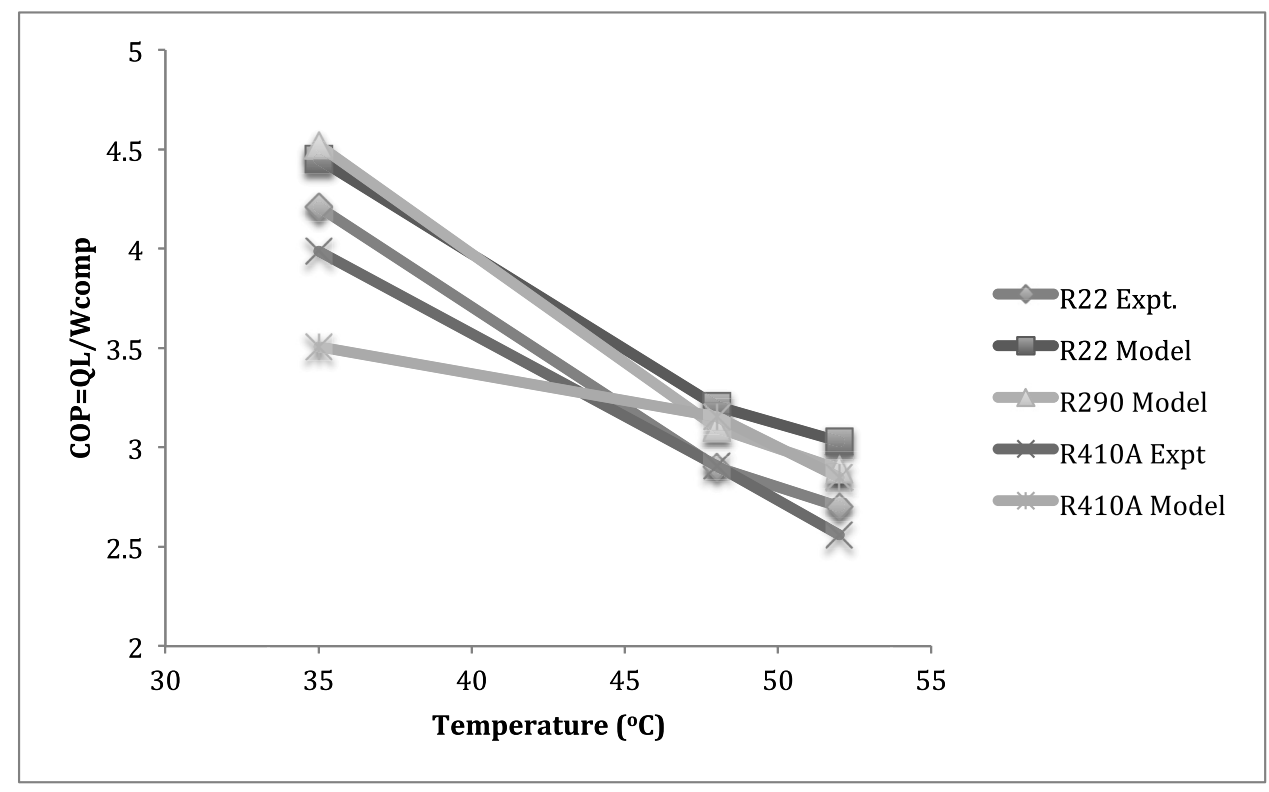

Fig. 5. COP calculated using compressor power versus ambient temperature.

Figure 6 represents the total power results versus the ambient temperature. It can be seen that the total power increases with an increase in ambient temperature. The experimental values were slightly higher than those of the model results. At $35^{\circ} \mathrm{C}$, the percentage error between the experimental and model results for R22 was $3.88 \%$. However, at $48^{\circ} \mathrm{C}$ and $52^{\circ} \mathrm{C}$, the percentage error was $8 \%$ and $8.72 \%$. For R410A, the percentage errors between the experimental and model results at $35^{\circ} \mathrm{C}, 48{ }^{\circ} \mathrm{C}$, and $52^{\circ} \mathrm{C}$ were $10.34 \%, 11.62 \%$, and $11.49 \%$. The total power of R22 was slightly higher than that of R410A. The total power results of R290 lie between R22 and R410A.

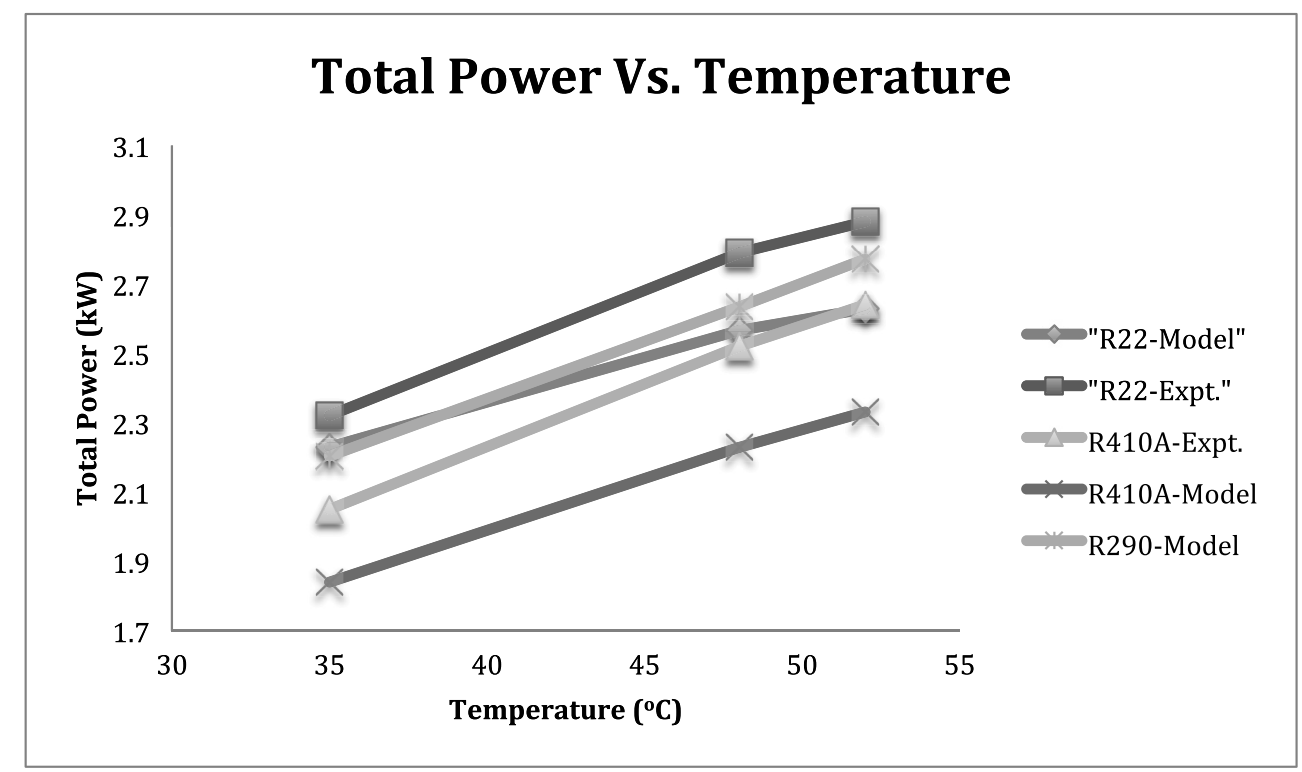

Fig. 6. Total power versus ambient temperature for R22. 
Figure 7 represents the results of the refrigeration effect versus the ambient temperature. It is clear that the refrigeration effect decreases with an increase in the ambient temperature. R290 had the highest refrigeration effect, while R410A had the lowest.

At $35^{\circ} \mathrm{C}$, the model and experimental refrigeration effects for $\mathrm{R} 22$ were $152.4 \mathrm{~kJ} / \mathrm{kg}$ and $163.1 \mathrm{~kJ} / \mathrm{kg}$. The percentage error between the experimental and model values was $6.56 \%$. At $48{ }^{\circ} \mathrm{C}$, the experimental and model results were equal to $140.125 \mathrm{~kJ} / \mathrm{kg}$ and $137.3 \mathrm{~kJ} / \mathrm{kg}$. The percentage difference was $2.02 \%$. Moreover, at $52^{\circ} \mathrm{C}$, the experimental and model refrigeration effects were approximately equal, and the percentage error was $0.12 \%$. The experimental and model percentage errors for $\mathrm{R} 410 \mathrm{~A}$ at $35^{\circ} \mathrm{C}, 48^{\circ} \mathrm{C}$, and $52^{\circ} \mathrm{C}$ were $2.62 \%, 1.65 \%$, and $0 \%$. The difference in the refrigeration effects between R290 and R22's model results at $35^{\circ} \mathrm{C}, 48$, and $52^{\circ} \mathrm{C}$ was $101.4 \mathrm{~kJ} / \mathrm{kg}, 77.8 \mathrm{~kJ} / \mathrm{kg}$, and $72.7 \mathrm{~kJ} / \mathrm{kg}$. Having a high refrigeration effect is desirable to maintain a cool atmosphere. The difference in refrigeration effects, at the three ambient temperatures, between R290 and R22 was fairly high.

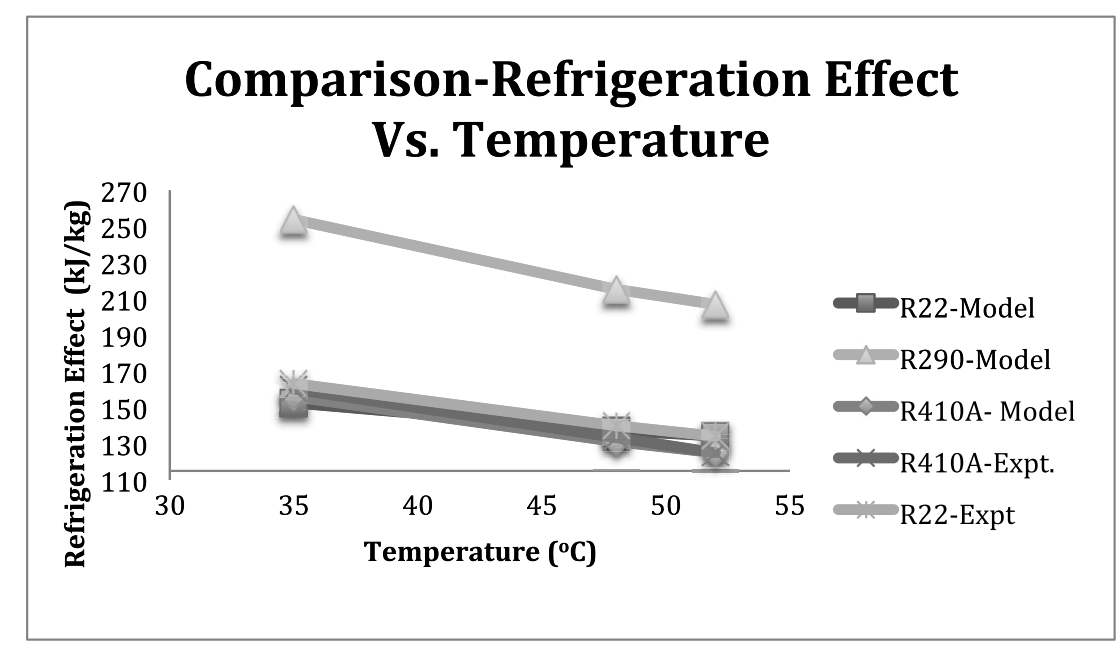

Fig. 7. Results of refrigeration effect versus ambient temperature for R22.

\subsection{Model Verification}

The model was tested on experimental data from a reference paper (Eltalouny \& Nielsen, 2016). The experiments of the paper were conducted on prototypes with approximately similar cooling capacities of the current work. The tests were carried out under the same testing specifications.

Tables 1, 2, and 3 show the results of a window unit prototype operated by R22 at three ambient temperatures: $35^{\circ} \mathrm{C}$, $48^{\circ} \mathrm{C}$, and $52^{\circ} \mathrm{C}$. The COP and power were validated using the model, and the percentage error was calculated. The percentage error of the COP and power at the three conditions was less than $15 \%$, proving that the model is applicable. The model was also verified for R290 using the same reference (Eltalouny \& Nielsen, 2016). The prototype used in this case was a decorative split unit. The details of the unit at the three conditions are shown in tables 4, 5, and 6 . At the three ambient conditions, the percentage error did not exceed 13\%, confirming the model's credibility for R290.

Table 1. Results at $35^{\circ} \mathrm{C}$ for R22

\begin{tabular}{|c|c|c|c|}
\hline Parameters & $\begin{array}{c}\text { Experimental Results } \\
\mathbf{a t ~ 3 5}^{\circ} \mathbf{C}\end{array}$ & Model Results at $\mathbf{3 5}^{\circ} \mathbf{C}$ & \% Error \\
\hline COP & 2.77 & 2.41 & 14.9 \\
\hline Power $(\mathrm{kW})$ & 1.906 & 2.186 & 12.8 \\
\hline
\end{tabular}


Table 2. Results at $48^{\circ} \mathrm{C}$ at $\mathrm{R} 22$

\begin{tabular}{|c|c|c|c|}
\hline Parameters & $\begin{array}{c}\text { Experimental Results } \\
\mathbf{a t ~}^{\mathbf{4}} \mathbf{C}\end{array}$ & Model Results at $\mathbf{4 8}^{\mathbf{}} \mathbf{C}$ & \% Error \\
\hline COP & 1.90 & 1.85 & 2.7 \\
\hline Power $(\mathrm{kW})$ & 2.340 & 2.398 & 2.4 \\
\hline
\end{tabular}

Table 3. Results at $52^{\circ} \mathrm{C}$ at $\mathrm{R} 22$

\begin{tabular}{|c|c|c|c|}
\hline Parameters & $\begin{array}{c}\text { Experimental Results } \\
\mathbf{a t ~ 5 2}^{\circ} \mathbf{C}\end{array}$ & Model Results at 52 & \% \\
\hline COP & 1.67 & 1.71 & 2.4 \\
\hline Power $(\mathrm{kW})$ & 2.471 & 2.421 & 2.1 \\
\hline
\end{tabular}

Table 4. Results at $35^{\circ} \mathrm{C}$ for $\mathrm{R} 290$

\begin{tabular}{|c|c|c|c|}
\hline Parameters & $\begin{array}{c}\text { Experimental Results } \\
\mathbf{a t ~ 3 5}^{\circ} \mathbf{C}\end{array}$ & Model Results at $\mathbf{3 5}^{\circ} \mathbf{C}$ & \% Error \\
\hline COP & 0.84 & 0.84 & 0 \\
\hline Power $(\mathrm{kW})$ & 2.029 & 2.026 & 0.15 \\
\hline
\end{tabular}

Table 5. Results at $48^{\circ} \mathrm{C}$ for R290

\begin{tabular}{|c|c|c|c|}
\hline Parameters & $\begin{array}{c}\text { Experimental Results } \\
\mathbf{a t ~ 4 8}^{\circ} \mathbf{C}\end{array}$ & Model Results at $\mathbf{4 8}^{\circ} \mathbf{C}$ & \% Error \\
\hline COP & 0.60 & 0.66 & 8.9 \\
\hline Power $(\mathrm{kW})$ & 2.470 & 2.250 & 9.8 \\
\hline
\end{tabular}

Table 6. Results at $52^{\circ} \mathrm{C}$ for $\mathrm{R} 290$

\begin{tabular}{|c|c|c|c|}
\hline Parameters & $\begin{array}{c}\text { Experimental Results } \\
\mathbf{a t ~ 5 2}^{\circ} \mathbf{C}\end{array}$ & Model Results at 52 ${ }^{\circ} \mathbf{C}$ & \% Error \\
\hline COP & 0.53 & 0.60 & 12.6 \\
\hline Power $(\mathrm{kW})$ & 2.599 & 2.300 & 13 \\
\hline
\end{tabular}

\subsection{CONCLUSIONS}

An experiment was carried out on an R22 and an R410A air conditioning system rated $7 \mathrm{~kW}$. The process parameters (pressure, temperature, and enthalpy changes) across the cycle components were determined. A model was then developed from an ideal compression refrigeration cycle including the process changes to generate an actual cycle, for R22 and R410A. The experimental results were verified using the model and were within a $15 \%$ error range. A simulation to the model was further executed to predict the performance of R290.

To ensure the model's credibility, external data from a reference paper (Eltalouny \& Nielsen, 2016) for R22 and R290 were tested, and the results were within the acceptable error range. 
Comparing thermophysical properties of R290 with R22 shows that R290 has lower density and viscosity than $\mathrm{R} 22$, which is beneficial to ease the circulation of the refrigerant. In addition, R290 has a higher thermal conductivity and specific heat. Higher thermal conductivity increases the rate of heat transfer, resulting in an improved cooling capacity.

It is clear that the performance of the three refrigerants degraded with the increase in the ambient temperature. The refrigeration effect of R290 was much higher than that of R22 and R410A, with a mass flow rate approximately half that of R22. A low mass flow rate is an advantage since faster circulation of the refrigerant will take place. Furthermore, the size of the compressor will be smaller, as well as the charging quantity.

The use of R410A in this paper was to demonstrate its performance at high ambient temperature, and whether it could be an effective replacement for R22. R410A has a high global warming potential, even more than that of R22. R410A can be considered as a transitional alternative, but not a long-term replacement. In conclusion, R290 can be considered as a promising alternative.

\section{REFERENCES}

Air Conditioning and Refrigeration Institute (ARI). 1989. Standard 210/240 - Unitary Air

Ajrawi, S., Alotaibi, S., \& Chakroun, W. (2016). Experimental Modeling and Simulation of High Ambient Temperature Refrigerants for Air Conditioning. Presented at the 6th International Conference on Energy Research and Development, State of Kuwait.

Al-Joudi, K.J. \& Abd Al-Amir, Q.R. (2014, January). Performance Evaluation of Small Scale Air-Conditioning System Using R22 and Alternative Refrigerants. Journal of Engineering, 20, 1. Baghdad, Iraq: Baghdad University.

Ashrae. 1988. Ansi/Ashrae Standard 37-1988, Methods of testing for rating unitary air-conditioning and heat pump equipment. American Society of Heating, Refrigerating and Air-Conditioning Engineers, Atlanta: ASHRAE.

Calm, J.M. \& Hourahan, G.C. (2001, November). Refrigerant Data Summary. Engineered Systems, 18(11): 74-88.

Çengel, Y.A. \& Boles, M.A. (2006). Thermodynamics: An Engineering approach (5th ed.). Boston, MA: McGraw-Hill College.

Chakravarthy, M.A. \& Kumar, M.L.S.D. (2012). Experimental Investigation of an Alternate Refrigerant for R22 in Window Air Conditioning System. International Journal of Scientific and Research Publications, 2(10): 1-7.

Chin, L. \& Spatz, M.W. (1999). Issues Relating to the Adoption of R-410A in Air Conditioning Systems. $20^{\text {th }}$ International Congress of Refrigeration. Sidney, Australia.

Conditioning and Air Source Heat Pump Equipment.

Domanski, P.A. (1999). Evolution of Refrigerant Application. International Congress on Refrigeration. Milan, Italy.

Eltalouny, A. \& Nielsen, O. (2016). Promoting Low-GWP Refrigerants for Air-Conditioning Sectors in High-Ambient Temperature Countries (PRAHA). United Nations Industrial Development Organization.

Faramarzi, R., Coburn, B., Mitchell, S., Lutton, J. \& Sarhadian, R. (2004, February 18). Performance Evaluation of Typical Five-Ton Roof Top Air Conditioning Units Under High Ambient Temperatures. Refrigeration and Thermal Test Center Design and Engineering Services Customer Services Business Unit Southern California Edison.

Grof, T. (2009). Preparing for HCFC phase-out: Fundamentals of uses, alternatives, implications and funding for Article 5 countries. United Nations Industrial Development Organization. Retrieved from https://www.inido.org/fileadmin/user_ media/Publications/Pub_free/Preparing_for_HCFC_phaseout.pdf

Hadya, B., Usha Sri, P. \& Suresh Akella. (2012, September 8-9). Comparative Study of Eco-friendly Refrigerants in a Lower Capacity Air-Conditioning System. Proceedings from ICMAE' 2012: International Conference on Mechanical and Automotive Engineering. Bangkok, Thailand.

Historical agreement on HFCs reached in Kigali. (2016, October 15). Retrieved from http://www.ccacoalition.org/en/news/ historical-agreement-hfcs-reached-kigali

Kabeel, A., Khalil, A., Bassuoni, M. \& Raslan, M. (2016). Comparative experimental study of low GWP alternative for R134a in 
a walk-in cold room. International Journal of Refrigeration, 69: 303-312. doi: 10.1016/j.ijrefrig.2016.06.017

Karagoz, S., Yilmaz, M., Comakli, O. \& Ozyurt, O. (2004). R134a and various mixtures of R22/R134a as an alternative to R22 in vapour compression heat pumps. Energy Conversion and Management, 45(2): 181-196. doi: 10.1016/s01968904(03)00144-4

Kondou, C. \& Koyama, S. (2015). Thermodynamic assessment of high-temperature heat pumps using Low-GWP HFO refrigerants for heat recovery. International Journal of Refrigeration, 53: 126-141. doi: 10.1016/j.ijrefrig.2014.09.018

Makhnatch, P., Mota-Babiloni, A., López-Belchí, A. \& Khodabandeh, R. (2019). R450A and R513A as lower GWP mixtures for high ambient temperature countries: Experimental comparison with R134a. Energy, 166: 223-235. doi: 10.1016/j. energy.2018.09.001

Meurer, C., Buyle, O. \& Paulus-Lanckriet, M., 1999. Comparison of R-22 and R-410A at elevated condensing temperatures, 20th International Congress of Refrigeration, IIR/IIF, Sydney, Australia.

Mohanraj, M., Jayaraj, S. \& Muraleedharan, C. (2009). Environment friendly alternatives to halogenated refrigerants-A review. International Journal of Greenhouse Gas Control, 3(1): 108-119. doi: 10.1016/j.ijggc.2008.07.003

Motta, S.F.Y. \& Domanski, P.A. (2000). Impact of Elevated Ambient Temperatures on Capacity and Energy Input to a Vapor Compression System. National Institute of Standards and Technology. Letter report for ARTI 21-CR Research Project: 60550010/605-50015. Gaithersburg, MD.

Motta, S.F.Y. \& Domanski, P.A. (2000). Performance of R-22 and its Alternatives Working at High Outdoor Temperatures. International Refrigeration Conference. Indiana, IN: Purdue University.

Network, A.J.M. Kigali deal: Agreement reached to phase out HFCs. Retrieved from http://www.aljazeera.com/news/2016/10/ kigali-deal-agreement-reached-phase-hfcs-161015075725587.html

Payne, W.V. \& Domanski, P.A. (2002). A Comparison Of An R22 And An R410A Air Conditioner Operating At High Ambient Temperatures. International Re igeration and Air Conditioning Conference. Paper 532.

Schultz, K.J. (2014). Performance of R410A and R22 Low GWP Alternative Refrigerants at Elevated Ambient Temperatures. Proceedings from: International Refrigeration and Air Conditioning Conference. Paper 1462. La Crosse, WI: Ingersoll Rand

Sun, J., Li, W. \& Cui, B. (2019). Energy and exergy analyses of R513a as a R134a drop-in replacement in a vapor compression refrigeration system. International Journal of Refrigeration. doi: 10.1016/j.ijrefrig.2019.12.014

Wells, W., Bivens, D., Yokozeki, A. \& Rice, C.K. (1999). Air Conditioning System Performance with R-410A at High Ambient Temperatures, presentation at seminar on Alternative Refrigerants for Unitary Heat Pumps and Air Conditioners. ASHRAE Annual Meeting. Seattle, WA.

Yan, G., Liu, Y., Qian, S. \& Yu, J. (2019). Theoretical study on a vapor compression refrigeration system with cold storage for freezer applications. Applied Thermal Engineering, 160, 114091. doi: 10.1016/j.applthermaleng.2019.114091

\section{Appendix}

\section{Uncertainty Analysis:}

Uncertainty analysis was calculated to quantify data validity and accuracy at the testing temperatures.

$\mathrm{COP}$ at $35^{\circ} \mathrm{C}$

$$
C O P=\frac{Q_{L}}{W_{\text {tot }}}
$$

$$
\begin{aligned}
& Q_{L}=\dot{m}\left(h_{1}-h_{4}\right) \quad(\mathrm{kJ} / \mathrm{kg}) \\
& W_{i n}=\dot{m}\left(h_{2}-h_{1}\right) \quad(\mathrm{kJ} / \mathrm{kg})
\end{aligned}
$$




$$
\begin{gathered}
\frac{\partial C O P}{\partial Q_{L}}=\frac{W_{t o t}}{\left(W_{t o t}\right)^{2}}=\frac{1}{W_{t o t}}=\frac{1}{2.32} \\
\frac{\partial C O P}{\partial W_{t o t}}=\frac{0-Q_{L}}{\left(W_{t o t}\right)^{2}}=\frac{-Q_{L}}{\left(W_{t o t}\right)^{2}}=\frac{-7.16}{(2.32)^{2}} \\
x_{1}=Q_{L}= \pm 2.5 \%=0.025 \\
x_{2}=W_{t o t}= \pm 0.95 \%=0.0095
\end{gathered}
$$

$R=C O P$

$$
\begin{gathered}
U_{x 1}=U_{Q_{L}}=\frac{0.025}{7.16}=3.49 \times 10^{-3} \\
U_{x 2}=U_{W_{t o t}}=\frac{0.0095}{2.32}=4.1 \times 10^{-3} \\
U_{C O P}= \pm\left[\left(\frac{Q_{L}}{C O P} \times \frac{\partial C O P}{\partial Q_{L}} \times U_{Q_{L}}\right)^{2}+\left(\frac{Q_{L}}{C O P} \times \frac{\partial C O P}{\partial Q_{L}} \times U_{Q_{L}}\right)^{2}\right]^{1 / 2} \\
U_{C O P}= \pm\left[\left(\frac{7.16}{3.086} \times \frac{1}{2.32} \times\left(3.49 \times 10^{-3}\right)\right)^{2}+\left(\frac{2.32}{3.086} \times \frac{-7.16}{(2.32)^{2}} \times\left(4.1 \times 10^{-3}\right)\right)^{2}\right]^{1 / 2} \\
U_{C O P}=5.386 \times 10^{-3}=0.53 \%
\end{gathered}
$$

COP at $48^{\circ} \mathrm{C}$

$$
\begin{gathered}
C O P=\frac{Q_{L}}{W_{t o t}}=\frac{6.24}{2.79}=2.34 \quad \\
x_{1}=Q_{L} \\
R=C O P \\
\frac{\partial R}{\partial x_{1}}=\frac{\partial C O P}{\partial Q_{L}}=\frac{1}{W_{t o t}} \\
U_{x 1}=U_{Q_{L}}= \pm 2.5 \% \\
x_{2}=W_{\text {tot }} \\
R=C O P \\
\frac{\partial R}{\partial x_{2}}=\frac{\partial C O P}{\partial W_{t o t}}=\frac{-Q_{L}}{W_{t o t}^{2}}
\end{gathered}
$$




$$
\begin{gathered}
U_{x 2}=U_{W_{t o t}}= \pm 0.95 \% \\
U_{C O P @ 48 C}= \pm\left[\left(\frac{Q_{L}}{C O P} \times \frac{\partial C O P}{\partial Q_{L}} \times U_{Q_{L}}\right)^{2}+\left(\frac{W_{t o t}}{C O P} \times \frac{\partial C O P}{\partial W_{t o t}} \times U_{W_{t o t}}\right)^{2}\right]^{1 / 2} \\
U_{C O P @ 48 C}= \pm\left[\left(\frac{6.24}{2.24} \times \frac{1}{2.79} \times\left(\frac{2.5 / 100}{6.25}\right)\right)^{2}+\left(\frac{2.79}{2.24} \times \frac{-6.24}{(2.79)^{2}} \times\left(\frac{0.95 / 100}{2.79}\right)\right)^{2}\right]^{1 / 2} \\
U_{C O P @ 48 C}=5.2496 \times 10^{-3}=0.53 \%
\end{gathered}
$$

COP at $52^{\circ} \mathrm{C}$ :

$$
\begin{gathered}
U_{R}=\frac{\sigma_{R}}{R}= \pm \sqrt{\left(\frac{x_{1}}{R} \frac{\partial R}{\partial x} U_{x 1}\right)^{2}+\left(\frac{x_{2}}{R} \frac{\partial R}{\partial x} U_{x 2}\right)^{2}} \\
C O P=\frac{Q_{l}}{W_{\text {tot }}}=\frac{6.09}{2.88}
\end{gathered}
$$

$x_{1}=Q_{L}=6.09$

$R=C O P=2.12$

$$
\begin{aligned}
U_{X 1} & =\frac{2.5 \times 10^{-2}}{6.09} \\
\frac{\partial c o p}{\partial Q_{L}} & =\frac{1}{W_{t o t}}=\frac{1}{2.88}
\end{aligned}
$$

$x_{2}=W_{t o t}=2.88$

$R=C O P=2.12$

$$
\begin{aligned}
& U_{X 2}=\frac{0.95 \times 10^{-2}}{2.88} \\
& \frac{\partial c o p}{\partial W_{t o t}}=-\frac{Q_{L}}{W_{t o t}^{2}}=-\frac{6.09}{2.88^{2}} \\
& U_{\operatorname{COP}_{52 c}}=\sqrt{\left(\frac{Q_{l} \partial C O P}{\operatorname{COP} \partial Q_{L}} U_{Q_{L}}\right)^{2}+\left(\frac{x_{2} \partial C O P}{R \partial W_{t o t}} U_{W_{t o t}}\right)^{2}} \\
& { }^{C O P}{ }_{52 c}=\sqrt{\left(\frac{6.09 \times 1 \times\left(2.5 \times 10^{-2}\right)}{2.12 \times 2.88 \times 6.09}\right)^{2}+\left(\frac{2.88 \times(-6.09)\left(0.95 \times 10^{-2}\right.}{2.12\left(2.88^{2}\right)(2.88)}\right)^{2}} \\
& U_{\mathrm{COP}_{52}=5.25 \times 10^{-3}=0.53 \%}
\end{aligned}
$$


The indoor and outdoor specifications of the psychrometric test facility are described as follows:

Indoor room specifications.

\begin{tabular}{|l|l|}
\hline Indoor Room Specifications & \multicolumn{1}{|c|}{ Range } \\
\hline Dry-Bulb Temperature $\left({ }^{\circ} \mathrm{F}\right)$ & 50 to $125\left(10\right.$ to $\left.52^{\circ} \mathrm{C}\right)$ \\
\hline Wet-Bulb Temperature $\left({ }^{\circ} \mathrm{F}\right)$ & 43 to $90\left(6\right.$ to $\left.32^{\circ} \mathrm{C}\right)$ \\
\hline Humidity $\%$ & \\
\hline Dew Point Range $\left({ }^{\circ} \mathrm{F}\right)$ & 35 to $80\left(2\right.$ to $\left.27^{\circ} \mathrm{C}\right)$ \\
\hline Uniformity $\left({ }^{\circ} \mathrm{F}\right)$ & $\pm 0.5^{\circ} \mathrm{F}\left(0.3^{\circ} \mathrm{C}\right)$ \\
\hline Control $\left({ }^{\circ} \mathrm{F}\right)$ & $\pm 0.2^{\circ} \mathrm{F}\left(0.1^{\circ} \mathrm{C}\right)$ \\
\hline
\end{tabular}

Outdoor room specifications.

\begin{tabular}{|l|l|}
\hline Outdoor room specifications & \multicolumn{1}{|c|}{ Range } \\
\hline Dry-Bulb Temperature $\left({ }^{\circ} \mathrm{F}\right)$ & 15 to $125\left(-9\right.$ to $\left.52^{\circ} \mathrm{C}\right)$ \\
\hline Wet-Bulb Temperature $\left({ }^{\circ} \mathrm{F}\right)$ & 13 to $90\left(-11\right.$ to $\left.32^{\circ} \mathrm{C}\right)$ \\
\hline Humidity \% & 15 to 90 \\
\hline Dew Point Range $\left({ }^{\circ} \mathrm{F}\right)$ & 5 to $80\left(-15\right.$ to $\left.27^{\circ} \mathrm{C}\right)$ \\
\hline Uniformity $\left({ }^{\circ} \mathrm{F}\right)$ & $\pm 0.5^{\circ} \mathrm{F}\left(0.3^{\circ} \mathrm{C}\right)$ \\
\hline Control $\left({ }^{\circ} \mathrm{F}\right)$ & $\pm 0.2^{\circ} \mathrm{F}\left(0.1^{\circ} \mathrm{C}\right)$ \\
\hline
\end{tabular}

Uncertainty Measurements

\begin{tabular}{|c|c|}
\hline Parameter & Uncertainty \\
\hline Temperature & $\pm 0.25 \%$ \\
\hline Pressure & $\pm 0.2 \%$ \\
\hline Flow Rate & $\pm 1.2 \%$ \\
\hline Cooling Capacity & $\pm 2.5 \%$ \\
\hline Power & $\pm 0.95 \%$ \\
\hline
\end{tabular}

Sample calculation for percentage pressure change:

$\%$ pressure change $=\frac{0.6-0.55}{0.6} \times 100=8.33 \%$ 